\title{
NACIONES MULTIÉTNICAS, CULTURA Y DEMOCRACIA CONVIVENCIAL
}

\begin{abstract}
Buatu Batubenge Omer*
RESUMEN: Este trabajo parte de la consideración de las exclusiones sociales en países multiétnicos como un gran obstáculo para el logro de la democracia. Con ello, postula que la debilidad de la democracia liberal ha sido "su incapacidad de integrar todos los elementos de la realidad social en la realización de sus objetivos". Busca responder a las siguientes preguntas: ¿Cómo superar la debilidad de la democracia liberal? ¿Cómo reconciliar el pueblo y las instituciones que lo rigen con su creatividad histórica y cultural? El texto propone la democracia convivencial como medio y forma gubernamental que permita atacar el problema de la exclusión desde la base de las necesidades y de las aspiraciones de la población. Su objetivo es propulsar el diálogo entre las instituciones democráticas vigentes y las formas de vida que definen y caracterizan nuestras sociedades.
\end{abstract}

PALABRAS CLAVE: Árbol para la contienda, Democracia convivencial, Diversidad, Inclusión, Historicidad cultural.

La filosofía política en su crítica a la democracia liberal en América Latina tiene casi un común denominador: esta democracia es excluyente. ${ }^{1}$ En este sentido, Henri Favre advierte:

El problema fundamental de las sociedades latinoamericanas ya no es la dominación ni la explotación que las ciencias sociales han puesto durante

* Facultad de Filosofía y Letras, UNAM (omerbuat@yahoo.com).

${ }^{1}$ Cfr. Pablo González Casanova, Democracia y Estado multiétnico, México, UnAM, 1996; "La democracia de todos", en Emir Sader, Democracia sin exclusiones ni excluidos, Nueva Sociedad, 1998, pp. 23-34; Francisco Hidalgo, "Gouvernance et démocratie", Alternatives Sud, vol. VI, núm. 3, 1999; Samir Amin, La mondialisation économique et l'universalisme démocratique; Eduardo Saxe-Fernández, "Les facteurs limitants externes et internes de la Démocratie en Amérique", entre otros autores. 
mucho tiempo en el centro de sus preocupaciones. Se trata ahora de la exclusión. ${ }^{2}$

Además, Pablo González Casanova confirma que los investigadores han entorpecido la visión al respecto porque en sus trabajos, en las ideologías y en las prácticas de los movimientos políticos "la democracia de todos" no fue un objetivo central.

Parto de estas premisas y ubico este trabajo en el campo de la inclusión democrática, con la hipótesis de que la debilidad de la democracia liberal ha estado en "su incapacidad de integrar todos los elementos de la realidad social en la realización de sus objetivos". ${ }^{3}$ Busco responder a las siguientes preguntas: ¿Cómo superar la debilidad de la democracia liberal? ¿Cómo reconciliar a nuestro pueblo con su creatividad histórica y cultural? Para ello analizo primero lo que es una nación multiétnica, en segundo lugar planteo el problema de "la reivindicación de la inclusión" y finalmente propongo la democracia convivencial como medio y forma gubernamental, que permitirá resolver el problema de la exclusión desde la base de las necesidades y de las aspiraciones de la población. Mi objetivo es propulsar el diálogo entre las instituciones democráticas vigentes y las formas de vida que definen y caracterizan a nuestras sociedades.

\section{DE LA NACIÓN MULTIÉTNICA}

\section{La nación}

Existen varios significados del término nación. Todos ellos se refieren a la relación entre el individuo, considerado como un ser aislado, y el Esta-

${ }^{2}$ Henri Favre, L’Amérique Latine, Évreux, Imprimerie Hérissey, 1998, p. 59.

${ }^{3}$ Retomo como hipótesis la conclusión a la cual llegué en mi trabajo "Los retos de la transhistoricidad de la racionalidad liberal”, Cuadernos Americanos, vol. 6, núm. 90, México, UNAM, 2000, pp. 214-229. 
do, cuerpo que abarca a todos y cada uno de los individuos. El concepto de nación emerge en la actual sociedad moderna de esta mutua relación entre individuo y Estado a fin de dar cuenta de los modos de estructuración de la sociedad civil. Sin embargo, podemos reducir estas concepciones a dos básicas: la concepción liberal voluntarista y la vertiente germánica cultural. ${ }^{4}$

\section{El rubro voluntarista de la nación}

La primera concepción tiene como representantes a Hobbes, Locke, Montesquieu y Rousseau. Para estos autores la nación es, con algunas diferencias, el resultado del consenso de voluntades. Esta corriente señala en el concepto nación los siguientes factores: la primacía del individuo sobre el Estado y el carácter jurídico-político formal de la nación, en tanto constituye una construcción autónoma a partir de un pacto o consenso de los individuos en torno al poder político. Montesquieu es quien va enfatizar además de la voluntariedad y del consenso la necesidad del “espíritu de la nación”. Como lo subraya Gurutz Jáuregui, se trata de tomar en cuenta las normas, instituciones, costumbres, usos, lengua, religión y vivencias particulares como elementos constitutivos importantes de la nación. Por consiguiente, la nación o la sociedad civil resulta también de los factores y relaciones socioculturales.

Esta moderación del individualismo voluntarista va a alcanzar su paroxismo con Rousseau, cuando se propone redescubrir a la comunidad y redefinir la colectividad. Al superar el egoísmo particularista de Hobbes y el utilitarismo posesivo de Locke, Rousseau señala la presencia de un sentimiento innato de sociabilidad entre los seres humanos y en sus distintas vivencias, un interés y un bienestar comunes que representan la voluntad general. Lo que propone Rousseau es considerar las

${ }^{4}$ Cfr. Gurutz Jáuregui, La nación y el Estado nacional en el umbral del nuevo siglo, Madrid, Centro de Estudios Institucionales, 1990, pp. 15-21. 
viejas formaciones sociales, superarlas y refundirlas mediante "un nuevo sentimiento, una nueva conciencia". ${ }^{5}$ En la concepción de este autor, ese sentimiento proviene de la voluntad general y es legitimado por ésta. Como resultado de ello la nación debe dejar de ser la tierra de los antepasados para ubicarse en las leyes, las costumbres y en la manera de ser que procede de estos nuevos modos; la nación se funda de ese momento en adelante en las relaciones entre el Estado y sus miembros. De esta manera Rousseau lucha para la conversión o la transformación de las viejas comunidades en nación.

Sin embargo, en la realidad esta pugna en lugar de constituir este crisol resultante de la transformación y refundición de las colectividades culturales preexistentes en la nación, va a configurar una realidad sustancialmente antagónica en ellas. Así que en lugar de operar a partir de o con las viejas naciones operará contra o/y al margen de ellas. Es esta ruptura la que define hoy en día la construcción de muchas naciones modernas en las que las agrupaciones antiguas han desaparecido o van desapareciendo y otras han sido recuperadas de manera privada. También las nuevas naciones se caracterizan por el papel que desempeña el individuo, quien finalmente se ha convertido de un sujeto propietario a un individuo sólo con relaciones puramente económicas.

\section{CONSECUENCIAS: DESAPARICIÓN DE LAS ETNIAS}

Muchos analistas ${ }^{6}$ reposan sus teorías en este núcleo para profesar la desaparición o el reemplazo de las etnias a favor de la nación. Tal es el

5 Ibid., p.18.

${ }^{6}$ Aludimos a múltiples estudios de vertiente estática, objetivista o sustantivista cuya concepción de los grupos étnicos se entiende a partir de su definición de entidades aisladas, constituidas por características culturales precisas. Véase a propósito Gerardo Zúñiga, "La dimensión discursiva de las luchas étnicas. Acerca de un artículo de María Teresa Sierra”, Alteridades, año 10, núm. 19, México, UAM, enero-junio, 2000, p. 57 columna 1. Esta corriente consta de autores como Schapera, Murdock, Nadel, 
caso de Ernest Gellner para quien la nación existe y es constructo de convicciones, de fidelidades y de solidaridad entre los hombres. ${ }^{7}$ Es el reconocimiento mutuo entre miembros de un grupo, o de una clase, lo que hace la nación. Con ello, enfatiza, a su manera, que la nación es el resultado de la voluntad de los particulares. Sin este reconocimiento mutuo y motivado, la nación no existe. Cuando Gellner se refiere a la noción de "modularidad" 8 como lo que permite a las particularidades hacer retoques necesarios en su identidad, que dejan de ser muy poderosas y rígidas, es para mostrar que estos retoques son inexistentes en lo que llama comunidades de sangre.

De la misma manera, los propósitos deshistorizantes de Elengu Pene Elengu parten de la definición de la nación como comunidad de voluntades individualistas. No es entonces casual que declare la guerra a las etnias para que desaparezcan como tales y se transformen en nación. Así señala: "ce qui est visée dans cette transformation c'est [...] la destruction de la société ethnique". 9 (El objetivo de esta transformación es la destrucción de la sociedad étnica). Y esto tiene su lógica en la repetición que hace de la definición individualista de la nación como una comunidad fundada sobre la voluntad de sus miembros: "un grupo humano bastante grande que se caracteriza por la conciencia de su unidad y la voluntad de vivir juntos". ${ }^{10}$

Singer, Narol, Caso, Aguirre Beltrán. Zúñiga cita otro grupo de autores muy importante pero poco valorado que se afirma en el carácter dinámico, relacional o subjetivo que estos autores atribuyen a la etnia. Ésta, para ellos, surge en situaciones plurales y se define a partir de la diferenciación cultural entre grupos interactuantes en un contexto preciso (Barth, Noerman, Leach, Balandier, Amselle.). Nuestro trabajo se inscribe, como lo indica su título, en este segundo grupo de autores.

${ }^{7}$ Ernest Gellner, Naciones y nacionalismo, México, Alianza/CNCA, 1991, p. 20.

${ }^{8}$ Ernest Gellner, Condiciones de la libertad. La sociedad civil y sus rivales, Barcelona, Paidós, 1996, pp. 100-107.

${ }^{9}$ Elengu Pene Elengu, "Entre ethnie et nation, l'État démocratique. Ethnicité et nationalité", en Canisius, Philosophie et politique en Afrique, Actes des Journées philosophiques, Kinshasa, Edit. Loyola, 1996, p. 11.

${ }^{10}$ Ibid., p. 13. 
No obstante la actualidad de estas rupturas y antagonismos, existen otras corrientes que creen en los valores culturales y que hacen depender la nación de ellos. Tal es el caso de la vertiente cultural-linguiística para la que la nación es una comunidad cultural.

\section{La concepción germánico-culturalista}

La corriente cultural es en verdad una reacción en contra del individualismo, del voluntarismo y del reduccionismo de la vertiente liberal pactista. Sus líderes son Herder y Fichte en Alemania. Así, para esta corriente la nación no se forma a partir de un universalismo abstracto que reposa en realidad sobre las pautas y cánones de las élites francesas, ni de una uniformidad cosmopolita ni tampoco de un raciocinio mecánico. Por consiguiente, Herder propone una alternativa que consiste en un universalismo fundamentado en la variedad y en la historia de cada pueblo. ${ }^{11}$ Para él, el pueblo es una entidad metafísica que se manifiesta mediante el volksgeist (espíritu del pueblo). En la manifestación del volksgeist, el factor más importante es la lengua, la cual es percibida como un acuerdo del alma que hace que el hombre sea hombre. De este modo, Herder va a identificar la nación con la lengua, que él considera como distintivo de cada pueblo.

La nación se convierte así en una comunidad cultural determinada por la lengua. Con este radicalismo, lo que reivindica Herder es la diversidad y la particularidad de cada pueblo y cada comunidad de lengua. Ésta se convierte en el criterio de la nación, porque por ella la división de la humanidad en distintos pueblos revela al mundo como un mundo de diversidad. Por eso, Fichte enfatizará el hecho de que el futuro de un pueblo depende sólo de la relación con su lengua. La culminación de esta nueva propuesta se encuentra en la reivindicación de la inclusión de todos, sin ninguna excepción en el sistema educacional para que desaparezca toda diferen-

${ }^{11}$ Jáuregui, op. cit., p. 20. 
cia de estamentos. La educación popular, porque es la que está aquí en juego, ayuda a regenerar a los pueblos y a liberarlos de la incultura, que es el mal principal contra la emancipación.

La consecuencia política de estas ideas lingüístico-culturales es la postulación de la necesidad de que las fronteras lingüísticas correspondan a los límites geográficos de un Estado. Lo que significaría que cada comunidad de lengua debe constituirse en Estado, éste pensado como el medio para el mantenimiento de la vida y el bienestar de todos. No es entonces casual que hoy en día haya reclamación de algunos grupos lingüísticos para constituirse en Estado.

Sin embargo, el radicalismo de esta teoría cultural de la nación corresponde al de la corriente precedente. No existe en la actualidad una nación unilingüística, casi todas las naciones son conjuntos de diferentes lenguas. Por lo que esta teoría se convierte a su vez en una ficción. Si se puede recoger algo de ella, es la insistencia en el valor de la diversidad, de la peculiaridad, de la historia de cada pueblo y de la educación popular que aparecen como sus pilares y no la erección de la lengua como criterio de lo nacional.

Justamente es a partir de esta diversidad y de la peculiaridad por lo que muchos autores buscan rescatar la relevancia del rubro cultural. Uno de estos autores es J. C. Cornejo Linares para quien la nación "es un producto de la historia". ${ }^{12}$ Es cierto que la cohesión y la homogeneidad que se dan en una nación provienen de la convivencia humana por mucho tiempo en un territorio determinado y cuando el grupo social se dedica a una actividad específica. La tierra desempeña un papel importante en la reducción de las diferencias raciales. Viviendo unida, esta comunidad tiene las mismas preocupaciones de defensa y de organización. Esto genera un vínculo espiritual común, cuyo resultado será la cultura común. Ésta se configura así como un conjunto de creencias,

12 J.C. Cornejo Linares, Política, nacionalismo, Estado, Buenos Aires, Cruz y Fierro Editores, 1966, p. 29. 
costumbres y opiniones. La presencia en el seno de esta comunidad de una lengua o una religión común tiende a reforzar esta unidad. ${ }^{13}$

Por último, Cornejo señala que si bien el territorio conformador de la cultura común es imprescindible en la formación de la nación, es sin embargo necesario que los integrantes de la comunidad tengan una conciencia suficiente de que son miembros de la misma comunidad y son diferentes de otras comunidades nacionales. Porque es esta conciencia la que los convierte en una comunidad histórica en la que todos participan sin excepción alguna. Esta colaboración se convierte, a su vez, en lo más importante para la actuación de cada miembro. Por lo que la realización plena de un miembro se concretiza en su contribución en la actividad comunitaria. En otras palabras, un miembro se forma en la medida en que coopera en la acción comunitaria.

Así pues, mientras la vertiente liberal individualista enfatiza en la nación la acción de la voluntad de los particulares, lo que se resalta en la corriente cultural es la diversidad y la peculiaridad histórica de cada grupo social. De esta manera el territorio, la proximidad y el tiempo se vuelven factores importantes, cuya combinación con la conciencia común de los miembros genera una unidad espiritual, una cohesión y una homogeneidad que se manifiestan en las creencias, opiniones, quehaceres y sentimientos.

La diversidad histórica y cultural son hoy las características generales de nuestras naciones. De este modo, cada sistema de gobierno tiene que adecuarse y comprometerse con ellas y no puede evadirlas. En este sentido, el concepto de nación si no se puede reducir a la voluntad de los individuos, no puede tampoco reducirse a una noción unilingüística. La nación debe entenderse en su relación dialéctica, es decir, en su composición multicultural y plural que llama al esfuerzo para la armonía. Sin una diversidad cultural e histórica, ninguna nación ni sistema de gobierno puede pretender alcanzar sus metas.

${ }^{13}$ Loc. cit. 


\section{LA NACIÓN MULTIÉTNICA Y LA REIVINDICACIÓN DE LA INCLUSIÓN}

Llegamos a la afirmación de que ninguna nación es hoy monolítica, es decir, constituida sólo por una etnia. Esta percepción es clara en nuestras naciones de América Latina, África, Asia y hasta de Europa. Entonces, ¿cuál podría ser la condición para el logro de una democracia con este tipo de nación? La multiplicidad de las etnias o grupos en nuestras naciones, su pluralidad es un factor patente de la diversidad que nos caracteriza. Por otro lado, la democracia podría definirse por una de sus características más importante: la diversidad o la pluralidad. Al respecto, Robert Dahl habla de la "poliarquía".

De este modo, la democracia debe entenderse a partir de la diversidad y sobre todo de una diversidad incluyente plenamente. No es casual, entonces, que refiriéndose a las democracias occidentales, Robert Dahl señala que la poliarquía en estos países es reciente, porque sólo trece la tenían. Y agrega:

[...] hasta nuestro siglo en ninguno de ellos el demos llegó a ser abarcador. [...] No sólo un gran porcentaje de la población adulta masculina estaba excluido en ellos del sufragio [...] las mujeres no votaron en las elecciones nacionales hasta después de la Segunda Guerra Mundial. La exclusión del sufragio implicaba asimismo estar excluido de muchas otras formas de participación. Y para concluir Dahl afirma: Así hasta el siglo XX todos los países "democráticos" estaban gobernados, en el mejor de los casos, por poliarquías masculinas. La proporción de adultas que efectivamente votaban era aun menor. $^{14}$

Esta larga cita subraya no sólo la importancia de la diversidad, sino también la de la inclusión de todos los factores sociales en el sistema de gobierno. E insiste en la participación de todos los miembros de la socie-

${ }^{14}$ Robert A. Dahl, La democracia y sus críticos, Barcelona, Paidós Ibérica, 2000, pp. 281-282. 
dad en la construcción de la comunidad. Además, cuando Dahl habla de países democráticos, pone la palabra "democrático" entre paréntesis como para subrayar sus reservas a calificarlos de democráticos.

Esto significa que también en nuestros países, mientras no contemos con todos los factores de la sociedad, con su inclusión y participación nunca podremos hablar de una verdadera democracia. Ésta no sólo tiene que comprenderse sin exclusiones, sino que la diversidad y la inclusión deben constituir el meollo de ella. Por eso, el doctor Pablo González Casanova advierte:

Ni el Estado de América Latina puede comprenderse sin una sociedad multiétnica, ni la construcción democrática, popular y nacional podrá dejar de expresar y representar a esa sociedad. La democracia participativa y representativa de América Latina, para serlo realmente deberá incluir y representar a las antiguas poblaciones de origen colonial y neocolonial como autonomía y como ciudadanía, o no será democracia. ${ }^{15}$

A su manera, este autor pone en relieve la necesidad de un Estado multiétnico para que éste y la democracia tengan sentido en América Latina. El texto se dirige directamente a los latinoamericanos, pero como lo dice él mismo en varias afirmaciones, ésta no es sólo la situación de América Latina, es también la de África, incluso de Asia y Europa.

De hecho, el autor también alude a las poblaciones coloniales y neocoloniales. En realidad se trata aquí de los indígenas de América. Estas poblaciones, arguye Pablo González Casanova, viven en un sistema global y capitalista que los domina, explota, excluye y los reproduce para mantenerlos sólo por su capacidad trabajadora. Sin embargo, en su perspectiva, considera a los "indios" como una categoría compleja que

15 Pablo González Casanova, "Las etnias coloniales y el Estado multiétnico", en Pablo González Casanova y Marcos Roitman Rosenmann [comps.], Democracia y Estado multiétnico en América Latina, México, La Jornada Ediciones/Centro de Investigaciones Interdisciplinarias en Ciencias y Humanidades-UNAM, 1996, p. 35. 
incluye a todos los dominados y explotados — los afro-americanos y asiático-americanos e incluso los mestizos y blancos pobres. La única diferencia entre éstos y los indios es el estatus inferior de los indios en la estratificación y en la sociedad neocolonial, y su organización en una comunidad política estructurada. ${ }^{16}$ Por eso para él, el indio es una categoría remanente de campesinos explotados, dominados y excluidos por el conquistador español y renovada por los herederos de éste.

A pesar de esta marginación, los indios se identifican por sus formas específicas de resistencia, de organización, de vivencia y de sobrevivencia. Estas formas constituyen la identidad india. Un Estado y una democracia que luchan por las libertades, la independencia y la soberanía, la participación de todos los miembros de la sociedad, la constitución de una comunidad política nacional, la felicidad de todos los miembros de la sociedad, deben tomar en cuenta esta especificidad india.

\section{DEMOCRACIA CONVIVENCIAL Y ESTADO MULTIÉTNICO}

Las naciones multiétnicas se han vuelto un rompecabezas para muchos filósofos, politólogos y sociólogos. Por lo que respecta a las naciones europeas, la solución que han encontrado es subsumir la etnia en la nación. Ante las resistencias han adoptado un sistema de exclusión de grupos numerosos en la construcción de las naciones. Basándonos en estas exclusiones, en la diversidad de nuestras naciones y con el objetivo de alcanzar un gobierno que tome en cuenta la participación de todos en los asuntos nacionales, postulamos, frente a la democracia liberal y excluyente imperante, la posibilidad de una democracia convivencial.

La democracia convivencial descansa sobre dos fuentes importantes: la contienda africana y el pensamiento democrático de Paul Ricoeur.

${ }^{16}$ Ibid., p. 29. 
La contienda africana (la deliberación, el parlamento tradicional $)^{17}$

El paradigma democrático de la contienda africana se explica a partir de la figura tradicional del árbol para la contienda.

\section{EL ÁRBOL PARA LA CONTIENDA}

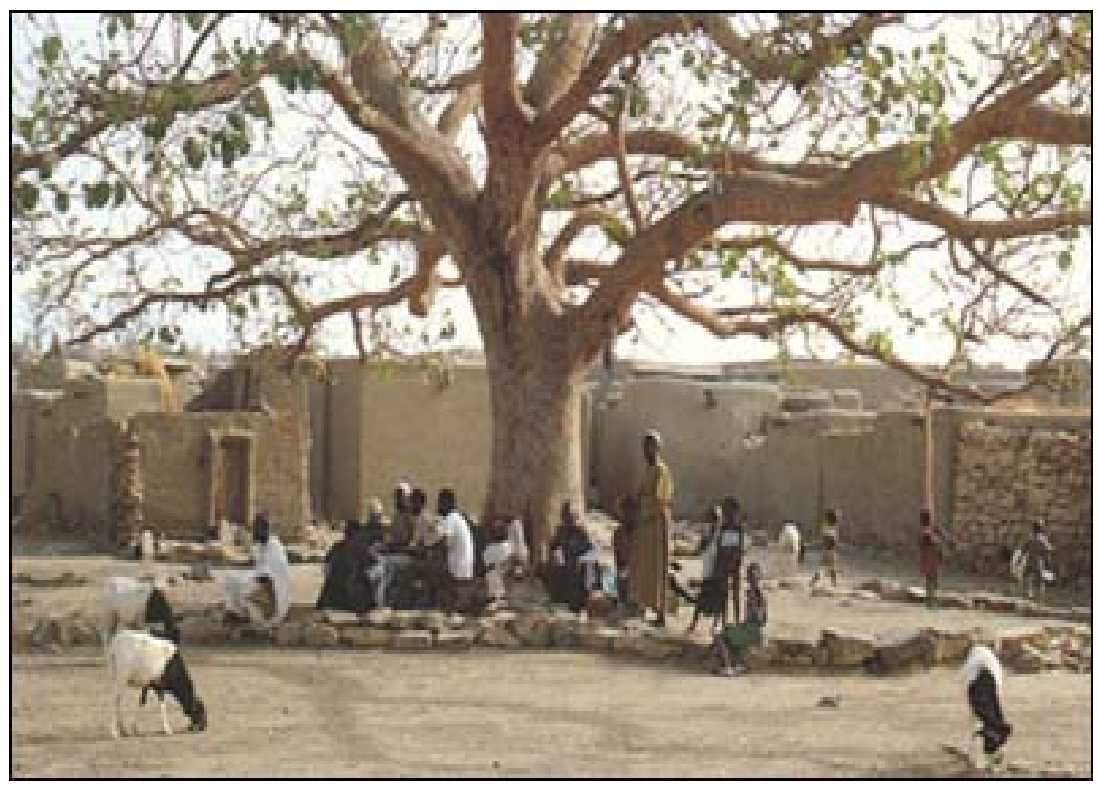

ILUSTRACIÓN: Árbol para la contienda (o parlamento tradicional africano).

${ }^{17}$ Para América Latina, véase la contienda en lo que Carlos Lenkersdorf llama "reuniones comunitarias". Carlos Lenkersdorf, Filosofar en clave tojolabal, México, Miguel Ángel Porrúa, 2002, cap. 4 "El nosotros en el contexto socio-político”, pp. 71-85. En estas páginas, Lenkersdorf señala que el nosotros es el símbolo del proceso que lleva del caos al consenso, a la comunicación lograda. Efectivamente, en la contienda africana, lo que se busca es el consenso equilibrante a partir de la participación de todos, del "nosotros". 
EL ÁRBOL PARA LA CONTIENDA ES EL SÍMBOLO DE LA CULTURA DEMOCRÁTICA AFRICANA

Contienda (palabre en francés o palaver en inglés) significa el modo de discusión conflictiva del pueblo en la búsqueda de las soluciones para la armonía de la sociedad. En este sentido, cuando se habla de democracia tradicional africana, se está refiriendo al "modo de toma de decisiones y de arreglo de los problemas sociales". ${ }^{18}$

En la contienda se enfatizan las siguientes ideas o prácticas:

a) La idea africana de políticas de la comunidad que involucran a todo el mundo ( y no sólo a la mayoría).

b) El objetivo principal es el consenso considerado como el acuerdo de todos en la decisión final.

c) La idea de la cultura o identidad compartida que pone en relieve el carácter comunitario de la sociedad africana y del consenso como base de sus políticas.

d) La promoción de la unidad, de la apertura hacia todos.

e) El asegurarse de que todos los puntos de vista sean considerados e incluidos en el proceso de deliberación.

f) El jefe, cuando quiere dar la decisión, habla hasta convencer a todos y no se impone.

g) Miembros participantes: jefe, consejeros, pueblo ordinario, hombres y mujeres, jóvenes y por supuesto los sabios ancianos.

Entonces, cabe subrayar que "en la contienda africana, el consenso estriba en la decisión misma y no en su aceptación por la mayoría". ${ }^{19}$ En

${ }^{18}$ Omer Buatu Batubenge, Elementos histórico-culturales en la construcción de la democracia para África y su importancia para América Latina. El caso de la conferencia Nacional soberana africana, México, UNAM, 2003 [tesis de doctorado], p. 213.

${ }^{19}$ Ibid., pp. 214-215. Véase también Van Hensbroek, Pieter Boele, African political philosophy, 1860-1995. An inquiry into three families of discourse, Grafish Centrum Rug, University of Groningen (Netherlands) [s.f.], p. 186. 
breve, a mi parecer, la contienda africana es una postura incluyente de la democracia que me permite postular la democracia convivencial. Por supuesto existe una jerarquía sociopolítica, pero todo el mundo tiene el derecho de participar en la discusión e idear sobre la manera de restablecer la calma, la paz y la convivencia.

\section{Teoría democrática de Paul Ricoeur}

La concepción democrática de Paul Ricoeur es doble. Él la entiende con respecto a los conflictos sociales y al concepto de poder como su teleología. De allí los dos ejes de su definición de democracia. Respecto a los conflictos, la democracia es un estado que no se propone eliminarlos, sino más bien inventar los procesos que permitan expresarlos y puedan seguir siendo negociables. ${ }^{20}$ La base de este eje es el debate abierto y el acuerdo mutuo, siempre reconstruyéndose.

Por lo que se refiere al concepto de poder, la democracia es el régimen en el cual la participación en la toma de decisiones se hace por un número siempre mayor de ciudadanos, por lo cual disminuye la distancia entre el sujeto y el soberano. ${ }^{21}$ Esto es la participación, porque en este eje se insiste en que el gobierno democrático supone que cuanto más intervenga la gente en la dirección de la política, es más probable que ésta refleje sus preocupaciones y aspiraciones. De hecho, son los ciudadanos los que experimentan los efectos de la política gubernamental en la práctica. Y esta última sólo reflejará esta experiencia si existen canales eficaces y sistemáticos de influencia y de presión de la base popular.

La consecuencia general de esta doble definición es que no hay democracia donde faltan la diversidad y la pluralidad. Y cuando existe la diversidad, debe hallarse el modo de expresarla. Para Paul Ricoeur y

${ }^{20}$ Cfr. Paul Ricoeur, "Ethique et politique”, Communio, núm. 6, julio de 1976, p. 9.

${ }^{21}$ Ibid., p.10. 
para nosotros, el método de expresión de la diversidad y de la resolución de las divergencias es el debate abierto.

Además la democracia así definida se percibe como una idea reguladora opuesta a la acepción del sistema de gobierno que tiene una estructura piramidal según la cual es el jefe, quien dicta todo lo que los de abajo, el pueblo, tienen que hacer.

\section{De la democracia convivencial}

Como consecuencia de la diversidad, encuentro el concepto de convivencia adecuado para construir una democracia. Debido a la numerosa cantidad de grupos que componen nuestras naciones, la concepción de la democracia que defiendo es la que intenta promover la interacción social a partir de la inclusión de todos los miembros y los grupos sociales con todas sus preocupaciones en la construcción de la comunidad.

Atribuyo a esta concepción el término de democracia convivencial para enfocar la democracia como experiencia de vida, como conjunto de experiencias de los actores sociopolíticos en busca de la construcción de una unidad desde la diversidad. Además, el término de convivencia tiene este poder de evocar que fuera de la pluralidad, no existe la democracia.

La convivencia es un conjunto de vivencias armónicas y de las fuerzas sociales centrífugas que definen la relación entre los individuos y entre los diferentes grupos de que éstos son parte. En ella la vida democrática se logra sólo gracias a la solidaridad, la cooperación y la participación.

La democracia convivencial es ante todo una visión estética de la contienda africana. La razón de ello es que en la estética confluyen creatividad, intencionalidad, y sueño de hacerse y no dejar al otro decir de mí lo que soy antes de que me conozca. La democracia convivencial es el sueño de exteriorizarse tal como uno es frente a los demás y en colaboración con los demás. 
Se trata de defenderse contra el sistema de gobierno que tiene una estructura piramidal, tal como prevalece en muchos países de África y América Latina. Existen el jefe y los dirigentes, pero ellos gobiernan a partir de las aspiraciones del pueblo, de sus necesidades y de la confianza que el pueblo confiere a estas instituciones en el ejercicio de sus actividades. De este modo, el poder político no es el control de la fuerza sino el encuentro de aspiraciones y la capacidad de canalizarlas para su expresión. Ésta, me parece, la gran idea que se perfila en la realización del edificio democrático.

Considerada sólo como sistema de gobierno para la toma de decisiones grupales, la democracia tiene el defecto de desposeer de la savia vivificante que le permitiría tener buenos resultados.

\section{Desafíos para el logro del diálogo y perspectivas}

A mi parecer, el gran desafío para el logro del diálogo y, por consiguiente, de la democracia convivencial es la creación de estrategias de gestión o administración para que ésta no degenere en la partición de las naciones. Pienso aquí, por ejemplo, en la caída del Imperio romano occidental sólo trescientos años después de su separación, mientras que el Imperio bizantino duraría diez siglos.

Este desafío es una responsabilidad de todas las naciones multiétnicas para cooperar en la creación de estructuras capaces de generar la participación, la inclusión y la convivencia de todos sin marginación ni exclusión.

Creo que, hoy en día, Brasil y Venezuela están viviendo una experiencia interesante de democracia que puede inspirar a muchas de nuestras naciones para la inclusión de todos. Pienso en el acuerdo con los pueblos indígenas para su pleno desarrollo y participación en la construcción del país en todos los niveles y sobre todo en la integración de este acuerdo en el texto de la Constitución. En África, cabe subrayar el caso de Madagascar, Benin y Malí que tratan, a su manera, de vivir una experiencia incluyente de la sociedad democrática. 


\section{CONCLUSIONES}

Estoy convencido que el camino adecuado para el rescate y la consolidación de la democracia latinoamericana es precisamente la consideración del paradigma de la "democracia convivencial" a fin de reconciliarnos con la historia y la cultura, de abrir y mantener abiertos el espacio público y los espacios originales de la formación de la población, como las familias o las etnias; para así pensar finalmente en la democracia en el marco de la inclusión de todos. Termino con Mario Magallón afirmando: "La democracia (en América Latina) afirma el derecho de los ciudadanos a una vida mejor; está planeada y conscientemente dirigida a la inclusión de todos los seres humanos, como ciudadanos y miembros de diversas colectividades". ${ }^{22}$ Entonces, la democracia en América Latina debe ser una democracia de todos. Lo será si sólo se la concibe como convivencial.

\section{BIBLIOGRAFÍA}

A. DAHL, RoBert, La democracia y sus críticos, Barcelona, Paidós Ibérica, 2000.

, "Los retos de la transhistoricidad de la racionalidad liberal", Cuadernos Americanos, núm. 90, México, UNAM, noviembre-diciembre 2001, pp. 214-229.

CALCUTT, RichaRD, "Vers quelle démocratie", in Relations, mai 1998, pp. 105-108.

Cornejo Linares, J. C., Política, nacionalismo, Estado, Buenos Aires, Cruz y Fierro Editores, 1966.

22 Mario Magallón Anaya, La democracia en América Latina, México, Plaza y Valdés/ CCyDEL, 2003, p. 382. 
E. SAXE-FERnÁndeZ, EduARdo, "Les facteurs limitants externes et internes de la Démocratie en Amérique”, Alternatives Sud, vol. VI, núm. 3, 1999.

Elungu Pene Elungu, "Entre ethnie et nation, l'État démocratique. Ethnicité et nationalité", in Canisius, Philosophie et politique en Afrique, Actes des Journées philosophiques, Kinshasa, Edit. Loyola, 1996, pp. 9-16.

GELlner, ERnest, Condiciones de la libertad. La sociedad civil y sus rivales, Paidós, Barcelona, 1996.

, Naciones y nacionalismo, México, Alianza/CNCA, 1991.

González CASAnOVA, PABlo, "La democracia de todos", en Emir Sader, Democracia sin exclusiones ni excluidos, Nueva Sociedad, 1998, pp. 23-34.

, "Las etnias coloniales y el Estado multiétnico", en Pablo González Casanova y Marcos Roitman Rosenmann [comps.], Democracia y Estado multiétnico en América Latina, México, La Jornada Ediciones/Centro de Investigaciones Interdisciplinarias en Ciencias y Humanidades-UNAM, 1996, p. 35.

, Democracia y Estado multiétnico, México, UnAM, 1996.

HENRI FAVRE, L'Amérique Latine, Évreux, Imprimerie Hérissey, 1998, p. 59.

HidAlgo, Francisco, "Gouvernance et démocratie", Alternatives Sud, vol. VI, núm. 3, 1999.

JÁUREGUI, GuRUTZ, La nación y el Estado nacional en el umbral del nuevo siglo, Madrid, Centro de Estudios Institucionales, 1990, pp. 15-21.

Lenkersdorf, CARlos, Filosofar en clave tojolabal, México, Miguel Ángel Porrúa, 2002, 273 pp.

Magallón Anaya, Mario, La democracia en América Latina, México, Plaza y Valdés/CCydel, 2003, p. 382.

OMER BuAtu BAtubenge, "La relacionalidad étnica", Cuadernos Americanos, núm. 95, México, UNAM, septiembre-octubre, 2002, pp. 143-160. 
RICOEUR, PAUl, "Ethique et politique”, Communio, núm. 6, julio de 1976. SAMIR AMIN, "La mondialisation économique et l'universalisme démocratique”, Alternatives Sud, vol. VI, núm. 3, 1999.

ZúÑIGA, GERARDO, "La dimensión discursiva de las luchas étnicas. Acerca de un artículo de María Teresa Sierra", Alteridades, año 10, núm. 19, México, UAM, enero-junio, 2000. 